05,12

\title{
Морфология и магнитные свойства полых сфер $\mathrm{Co}_{3} \mathrm{O}_{4}$
}

\author{
() А.В. Дмитриев ${ }^{1}$, Е.В. Владимирова ${ }^{1, \uparrow}$, А.П. Есаулков ${ }^{1}$, В.Д. Журавлев ${ }^{1}$, М.В. Кузнецов ${ }^{1}$, С.А. Упоров ${ }^{2}$ \\ ${ }^{1}$ Институт химии твердого тела УрО РАН, \\ Екатеринбург, Россия \\ ${ }^{2}$ Институт металлургии УрО РАН, \\ Екатеринбург, Россия \\ ฯ E-mail: vladimirova@ihim.uran.ru
}

Поступила в Редакцию 20 августа 2020 г.

В окончательной редакции 20 августа 2020 г.

Принята к публикации 26 августа 2020 г.

\begin{abstract}
Методом ультразвукового спрей-пиролиза синтезированы наноструктурированные полые сферы $\mathrm{Co}_{3} \mathrm{O}_{4}$. Нанокристаллы, формирующие структуру сфер, отличаются размером и плотностью упаковки в зависимости от условий синтеза. Образцы аттестованы методами рентгеновской дифракции, сканирующей электронной микроскопии, низкотемпературной сорбции азота, вакуумной пикнометрии, КР- и РФЭ-спектроскопии. Полевые и температурные зависимости намагниченности показали, что размер и плотность упаковки нанокристаллов определяют магнитные характеристики и температуру Нееля полых сфер $\mathrm{Co}_{3} \mathrm{O}_{4}$.
\end{abstract}

Ключевые слова: ультразвуковой спрей-пиролиз, полые сферы $\mathrm{Co}_{3} \mathrm{O}_{4}$, слабый ферромагнетизм, обменное смещение, температура Нееля.

DOI: 10.21883 /FTT.2020.12.50294.173

\section{1. Введение}

Наноструктурированные магнитные материалы представляют интерес как с точки зрения фундаментальной науки, так и для ряда прикладных задач, например, в спинтронике, магнитооптических устройствах и биомедицине, хранения данных со сверхвысокой плотностью и т. д. $[1,2]$. На сегодняшний день магнитные наноструктуры получены в виде наносфер [3], нанобоксов [4], наноколец [5], нанопроволок/стержней/трубок [6] и тонких пленок [7]. Магнитные свойства наноструктурированных материалов определяются размером, формой и пространственным расположением наночастиц.

Полые сферы представляют интерес благодаря низкой плотности и большому объему пор, они могут быть использованы в медицинской диагностике и для контролируемого высвобождения лекарств $[8,9]$, накопления и преобразования энергии $[10,11]$, в фотокатализе $[11,12]$, химических сенсорах $[13,14]$. Перспективным материалом для такого рода задач может выступать оксид кобальта $\mathrm{Co}_{3} \mathrm{O}_{4}$. Объемный $\mathrm{Co}_{3} \mathrm{O}_{4}$ представляет собой антиферромагнетик (AFM), имеющий температуру Нееля $\left(T_{\mathrm{N}}\right)$ ниже $40 \mathrm{~K}[15,16]$. Магнитные моменты в $\mathrm{Co}_{3} \mathrm{O}_{4}$ возникают благодаря ионам $\mathrm{Co}^{2+}$, в основном, из-за спинов с небольшим вкладом спин-орбитального взаимодействия [17]. Ионы $\mathrm{Co}^{3+}$ в октаэдрических позициях являются диамагнитными вследствие расщепления $3 d$-уровней октаэдрическим кристаллическим полем и полного заполнения уровней $t_{2 g}$. Исследование наночастиц $\mathrm{Co}_{3} \mathrm{O}_{4}$ показало образование метастабильных состояний, таких как суперпарамагнитное и спиновое стекло [17-19], связанных с увеличением площади поверхности нанокристаллов. По данным [20], наночастицы $\mathrm{Co}_{3} \mathrm{O}_{4}$, диспергированные в $\mathrm{SiO}_{2}$, проявляют супер- парамагнитное поведение с температурой блокировки $T_{B}=3.4 \mathrm{~K}$. В работе [21] обнаружен антиферромагнитный переход при $26 \mathrm{~K}$ для частиц размером $17 \mathrm{~nm}$, в то время как для объемных образцов $1-2 \mu$ m подобный переход наблюдался при $30 \mathrm{~K}$. Дополнительно авторы [21] зафиксировали слабый ферромагнетизм (FM) ниже температуры Нееля и эффект обменного смещения петли гистерезиса. Mousavand с соавторами [22] установили зависимость $T_{\mathrm{N}}$ от размера частиц в $\mathrm{Co}_{3} \mathrm{O}_{4}$ и наблюдали увеличение намагниченности при температуре $T_{f}=10 \mathrm{~K}$ [22] связанное с взаимодействием некомпенсированных моментов на поверхности кристалла.

Значительно меньше публикаций посвящено исследованию магнитных свойств наноструктурированных материалов. Природа таких материалов определяется не только свойствами наночастиц, но и взаимодействием между ними. Системы взаимодействующих магнитных наночастиц могут демонстрировать большое разнообразие явлений, которые представляют научный и практический интерес [23].

Магнитные свойства полых сфер $\mathrm{Co}_{3} \mathrm{O}_{4}$ обсуждались в работе [24]. Увеличение ферромагнитных характеристик (коэрцитивной силы и намагниченности) с уменьшением диаметра сфер авторы связали с ростом кривизны поверхностей. По нашему мнению, магнитные свойства определяются не только диаметром сфер, но и их морфологией (размером наночастиц и плотностью их упаковки в оболочке). В настоящее время влияние этих факторов на магнитные свойства полых сфер $\mathrm{Co}_{3} \mathrm{O}_{4}$ не исследовалось.

Одним из способов получения наноструктурированных материалов разной морфологии является самосборка. В частности, процесс самосборки реализуется при испарении растворителя из раствора прекурсора. 


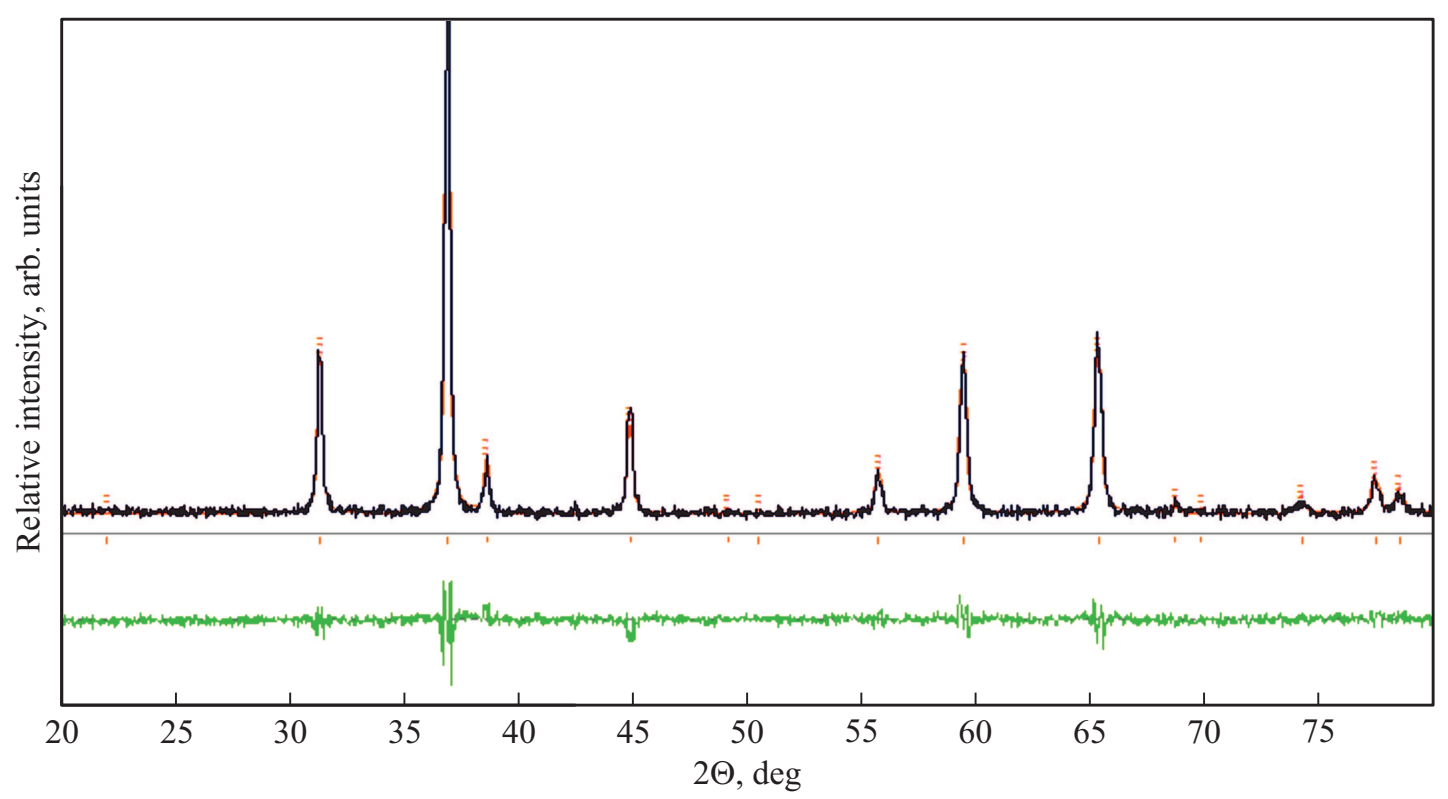

Рис. 1. Экспериментальная, расчетная и разностная рентгенограммы образца № $1 \mathrm{Co}_{3} \mathrm{O}_{4}$.

Конкуренция между скоростями испарения растворителя и диффузии растворенных компонент приводит к переходу от случайного распределения растворенных частиц к фиксированному с определенной морфологией. Среди различных методов синтеза ультразвуковой спрей-пиролиз (USP) является простым и универсальным подходом, позволяющим управлять процессом самосборки полых сфер из растворов. Изменяя скорость удаления растворителя (за счет варьирования температуры сушки капель аэрозоля) и скорость диффузии растворенных компонент (за счет образования металлоорганических комплексов), получают сферы различной морфологии [25,26,27].

Цель работы: методом ультразвукового спрей-пиролиза получить сферические полые сферы $\mathrm{Co}_{3} \mathrm{O}_{4}$ с различной плотностью оболочки и установить влияние размера наночастиц и плотности их упаковки на магнитные свойства.

\section{2. Эксперимент}

Синтез $\mathrm{Co}_{3} \mathrm{O}_{4}$ проводили из раствора нитрата кобальта с концентрацией $1.75 \mathrm{~mol} / \mathrm{l}$. Для синтеза использовалась установка для ультразвукового спрей-пиролиза (USP) с частотой ультразвука $1.7 \mathrm{MHz}$ [28]. Аэрозоль потоком воздуха со скоростью $14.6 \mathrm{ml} / \mathrm{s}$ подавалась в трубчатую печь, состоящую из двух частей: сушки капель аэрозоля и синтеза. После синтеза порошок улавливался электрофильтром. Нами синтезированы три образца: № 1 - из нитратного раствора при температуре сушки $623 \mathrm{~K}$, № 2 - из нитратного раствора при температуре сушки $723 \mathrm{~K}$ и № 3 - из нитратного раствора с добавлением 2 молей винной кислоты на 1 моль $\mathrm{Co}_{3} \mathrm{O}_{4}$ при температуре сушки $623 \mathrm{~K}$. Температура синтеза всех образцов составляла $1173 \mathrm{~K}$.
Для фазового анализа использовался дифрактометр XRD-7000 (SHIMADZU) с вторичным монохроматором с излучением $\mathrm{Cu} K_{\alpha}$ в диапазоне $2 \theta$ от 20 до $80^{\circ}$ с шагом $0.03^{\circ}$. Рентгеноструктурные исследования проводили на автоматическом дифрактометре STOE STADI-P, оборудованном линейным детектором мини-PSD с использованием излучения $\mathrm{Cu} K_{\alpha}$ в диапазоне $2 \theta$ от 5 до $120^{\circ}$ с шагом $0.02^{\circ}$. В качестве внешнего стандарта выступал поликристаллический кремний $(a=5.43075(5) \AA)$. Морфологию сфер изучали с помощью сканирующего электронного микроскопа JEOL 6390 LA. Пористую структуру образцов исследовали методом низкотемпературной $(77 \mathrm{~K})$ сорбции азота на установке Micromeritics Gemini VII Surface Are and Porosity 2390t. Методами ВЕТ и ВJН определены параметры пористости. Измерения плотности проводились на вакуумной пикнометрической системе AccuPyc II 1340 (Micromeritics, США). Рентгеновские фотоэлектронные спектры (РФЭС) записывались на спектрометре VG ESCALAB MK II. В качестве возбуждающего рентгеновского излучения использовалась линия $\mathrm{Mg} K_{\alpha}(1253.6 \mathrm{eV})$ без монохроматора. Магнитные характеристики синтезированных образцов изучались на криогенном магнитометре VSM-5T с диапазоном полей \pm 50 кОе и температур 4-300 К. Спектры комбинационного рассеяния (КР) регистрировали на конфокальном рамановском дисперсионном спектрометре InVia Reflex (Renishaw, UK), оборудованном конфокальным микроскопом Leica DML, с Nd:YAG-лазером $(\lambda=533 \mathrm{~nm})$ в качестве источника возбуждения.

\section{3. Результаты и обсуждение}

По данным рентгенофазового анализа получены однофазные образцы $\mathrm{Co}_{3} \mathrm{O}_{4}$ со структурой шпинели, 

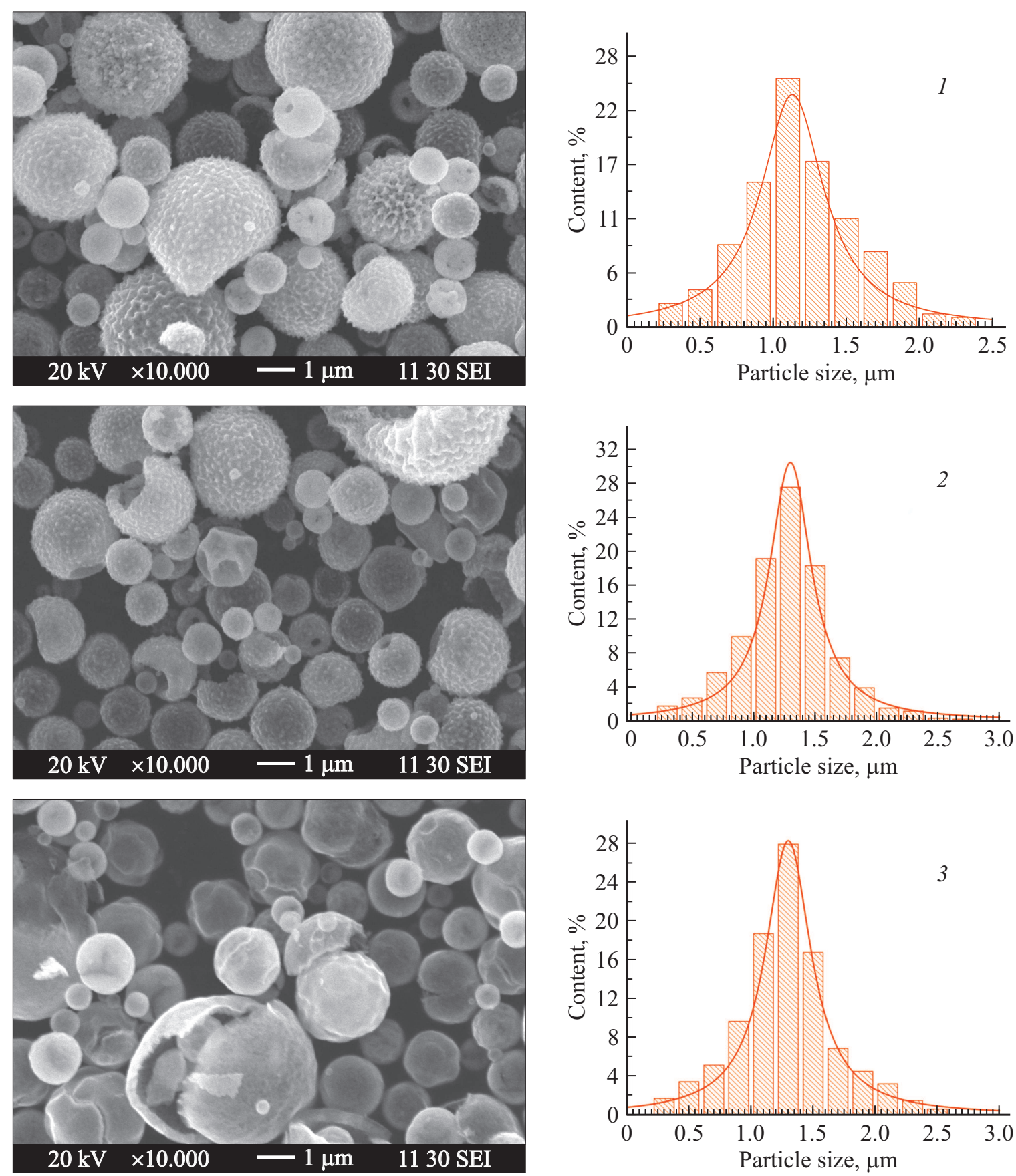

Рис. 2. СЭМ-изображения и гистограммы распределения сферических агломератов по размерам для образцов Со $\mathrm{O}_{4}\left(1-\right.$ обра- $^{2}$ зец № 1, 2 - образец № 2, 3 - образец № 3).

Результаты структурных и магнитных измерений

\begin{tabular}{c|c|c|c|c|c|c|c|c|c|c}
\hline Образец & $d, \mathrm{~nm}$ & $D, \mu \mathrm{m}$ & $\rho_{p}, \mathrm{~g} / \mathrm{cm}^{3}$ & $S, \mathrm{~m}^{2} / \mathrm{g}$ & $V_{p}, \mathrm{~cm}^{3} / \mathrm{g}$ & $T_{p}, \mathrm{~K}$ & $T_{f}, \mathrm{~K}$ & $T_{i r r}, \mathrm{~K}$ & $H_{c}, \mathrm{~T}$ & $H_{E}, \mathrm{~T}$ \\
\hline № 1 & 49.6 & 1.15 & 5.479 & 5.080 & 0.046 & 32 & 10 & 70 & 0.010 & 0.010 \\
\hline № 2 & 55.2 & 1.30 & 5.689 & 6.003 & 0.042 & 36 & 10 & 60 & 0.015 & 0.015 \\
\hline № 3 & 47.6 & 1.30 & 6.073 & 12.93 & 0.071 & 38 & 10 & - & 0 & 0
\end{tabular}


пр.гр. $F d 3 m$. Дифрактограммы всех образцов идентичны приведенной на рис. 1 для образца № 1. Установлено, что параметр элементарной ячейки $(a=8.077(3) \AA)$ не зависит от условий синтеза и близок к значению объемного образца [ICDD card 78-1969]. При помощи метода Ле Бейла с использованием подхода Klug \& Alexander [29], позволяющего определить вклад размерных эффектов в величину FWHM (полная ширина на половине высоты линии), были определены размеры областей когерентного рассеяния (CSR). Эти значения использованы для оценки размеров частиц, формирующих сферы $(d)$ (см. таблицу). Следует отметить, что уменьшение размеров кристаллитов часто приводит к увеличению параметра решетки [30]. В нашем случае он практически соответствует объемному состоянию $\mathrm{Co}_{3} \mathrm{O}_{4}$. Для наночастиц размером меньше $80 \mathrm{~nm}$ параметр решетки увеличивается до $8.1 \AA$ [30]. Для получения наночастиц нужного размера обычно варьируют температуру отжига в диапазоне $723-1073 \mathrm{~K}$, чем выше температура отжига тем больше размер зерен $\mathrm{Co}_{3} \mathrm{O}_{4}$. Наночастицы, полученные при температуре ниже $1073 \mathrm{~K}$ могут обладать вакансиями по кислороду, что и приводит к увеличению параметров решетки. Наши образцы синтезированы при $1173 \mathrm{~K}$. Сохранение параметров решетки может служить косвенным доказательством неизменности их стехиометрического состава.

Исследование порошков методом сканирующей электронной микроскопии (СЭМ) показало, что все образцы представляют собой агломераты сферической формы со средним диаметром $1.15-1.30 \mu \mathrm{m}$ (рис. 2, таблица). Экспериментально измеренная плотность образцов $\rho_{p}$ (таблица) меняется в диапазоне от $5.42 \pm 0.02$ до $6.06 \pm 0.02 \mathrm{~g} / \mathrm{cm}^{3}$. Видно, что в образце № 1 плотность существенно меньше значений, рассчитанных из данных рентгеноструктурного анализа $\left(\rho_{X R}=6.073 \mathrm{~g} / \mathrm{cm}^{3}\right)$.

Чтобы определить, являются ли полученные сферы полыми, мы измерили плотность образцов и оценили средний диаметр сфер $\mathrm{Co}_{3} \mathrm{O}_{4}$. Среднее значение диаметра сфер с плотностью $\rho_{p}$ можно оценить из закона сохранения массы $D_{c a l}=d_{d r o p}\left(C / \rho_{p}\right)^{1 / 3}$, где $C-$ концентрация раствора. Размер капель аэрозоля определяется выражением $d_{d r o p}=0.34\left(\pi \sigma / \rho_{L} f^{2}\right)^{1 / 3}$, где $\sigma-$ поверхностное натяжение $(\mathrm{N} / \mathrm{m}), \rho_{L}$ - плотность раствора $\left(\mathrm{kg} / \mathrm{m}^{3}\right)$, а $f$ - частота ультразвука (MHz) [31]. Измеренные нами плотность и поверхностное натяжение исходного нитратного раствора составили $1231 \mathrm{~kg} / \mathrm{m}^{3}$ и $0.063 \mathrm{~N} / \mathrm{m}$ соответственно. Добавление винной кислоты привело к увеличению плотности и поверхностного натяжения раствора до $1365 \mathrm{~kg} / \mathrm{m}^{3}$ и $0.068 \mathrm{~N} / \mathrm{m}$. Эти измерения позволяют вычислить средний диаметр капель аэрозоля $(2.50 \mu \mathrm{m}$ для нитратных растворов и $2.47 \mu \mathrm{m}$ для раствора с винной кислотой) и диаметр синтезированных сфер $(0.64$ и $0.62 \mu \mathrm{m}$ соответственно). Экспериментально измеренные средние значения диаметров сфер $(1.15-1.30 \mu \mathrm{m})$ в 2 раза превышают расчетные. Данный факт свидетельствуют о том, что

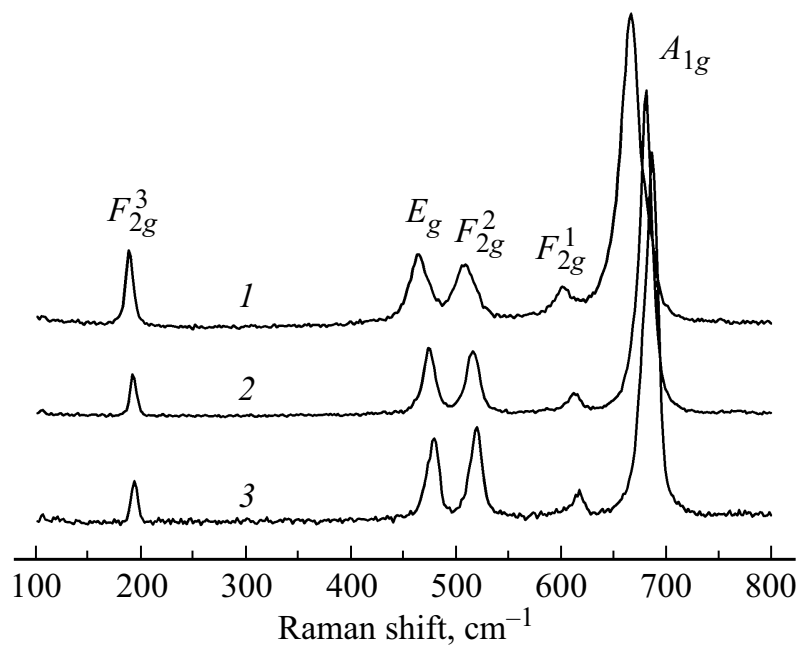

Рис. 3. Рамановские спектры образцов $\mathrm{Co}_{3} \mathrm{O}_{4}(1-$ образец № 1, 2 - образец № 2, 3 - образец № 3 ).

синтезированные образцы представляют собой полые сферы, а измеренная плотность отвечает не плотности всей сферы, а плотности оболочки.

Дополнительная информация о морфологии оболочек полых сфер получена из адсорбционных измерений. Изотермы адсорбции/десорбции всех образцов соответствуют второму типу согласно классификации IUPAC, что характерно для непористых или макропористых адсорбентов с размером пор порядка $50 \mathrm{~nm}$. Из приведенных в таблице данных экспериментов по адсорбции следует, что увеличение температуры сушки и введение винной кислоты увеличивает объем открытых пор и удельную поверхность образцов. С учетом результатов измерения плотности можно заключить, что в ряду образцов № 1-3 происходит выход закрытых пор на поверхность и уплотнение оболочки полых сфер.

Конфокальная комбинационная спектроскопия использована для изучения размерной зависимости фононного взаимодействия катионов кобальта в наночастицах, формирующих полые сферы $\mathrm{Co}_{3} \mathrm{O}_{4}$. На рис. 3 показаны спектры комбинационного рассеяния. Во всех образцах наблюдается пять основных фононных возбуждений $\left(F_{2 g}^{3}+E_{g}+F_{2 g}^{2}+F_{2 g}^{1}+A_{1 g}\right)$, которые хорошо согласуются со значениями, предсказанными теорией групп и совпадают с литературными данными [30-32]. Полоса в области $680 \mathrm{~cm}^{-1}$ рассматривается как симметричная валентная вибрация Со-О октаэдрической $\left(\mathrm{CoO}_{6}\right)$ группы, которая присваивается виду $A_{1 g}$ в спектроскопической симметрии $O h 7$. Рамановские полосы со средней интенсивностью в области $440-550 \mathrm{~cm}^{-1}$, имеют симметрию $E_{g}$ и $F_{2 g}^{2}$ соответственно, тогда как слабая зона, расположенная около $600 \mathrm{~cm}^{-1}$, имеет симметрию $F_{2 g}^{1}$. Полоса около $190 \mathrm{~cm}^{-1}$ относится к характеристикам тетраэдрических узлов $\left(\mathrm{CoO}_{4}\right)$ симметрии $F_{2 g}^{3}$. Этот результат подтверждает образование нанокристаллов $\mathrm{Co}_{3} \mathrm{O}_{4}$. Из сравнения КР-спектров образцов № 1 и 2 видно, что увеличение температуры сушки приводит к сужению и 
сдвигу линий в область более высоких частот. Такие изменения в спектрах КР характерны для нанокристаллов. Для образца № 1 размер нанокристаллов составляет $49 \mathrm{~nm}$, положение пиков $A_{1 g}$ и $F_{2 g}: 666.6$ и $180 \mathrm{~cm}^{-1}$ соответственно, в образце № $2-55 \mathrm{~nm}$ положение пиков $A_{1 g}$ и $F_{2 g}: 680$ и $192 \mathrm{~cm}^{-1}$, что близко к результатам, представленным в работе [30]. Существенные отличия наблюдаются в спектре образца № 3, положение пиков $A_{1 g}$ и $F_{2 g}: 685$ и $193 \mathrm{~cm}^{-1}$ соответственно. Несмотря на то, что сферы состоят из нанокристаллов с меньшим размером $46 \mathrm{~nm}$, в спектре КР наблюдаются узкие пики и их положение приближается к значениям, характерным для объемного образца $\left(A_{1 g}: 691 \mathrm{~cm}^{-1}\right)$. Авторы [32] отмечают, что КР-спектры наночастиц $\mathrm{Co}_{3} \mathrm{O}_{4}$ диаметром $30 \mathrm{~nm}$ сильно зависят от их состояния агломерации и эффектов теплового прогрева лазером. В этой части работы можно заключить, что структура оболочки сфер в образце № 3 существенно отличается от образцов № 1 и 2. Близость положения пиков в спектре КР к объемному состоянию $\mathrm{Co}_{3} \mathrm{O}_{4}$ и малая ширина позволяют предположить, что образец № 3 обладает более плотной упаковкой наночастиц, чем в образцах № 1 и 2.

Предполагается, что при использовании винной кислоты возможно частичное восстановление оксида кобальта на поверхности наночастиц. Для определения химического состава поверхности наночастиц, формирующих сферы $\mathrm{Co}_{3} \mathrm{O}_{4}$, проведено РФЭС-исследование. Данный метод не позволяет получить численные значения $\mathrm{Co}^{3+}$ и $\mathrm{Co}^{2+}$ с точностью выше 20\% [33], тем не менее изменение в соотношении $\mathrm{Co}^{3+} / \mathrm{Co}^{2+}$ приводит к видимому искажению спектров Сo $2 p$ за счет структуры сателлитов [34]. РФЭ спектры Со $2 p$ и О $1 s$ образцов № 1-3 полностью идентичны (рис. 4). В спектре Со $2 p$ наблюдается две линии при 780.0 и $795.2 \mathrm{eV}$, отвечающие ${ }^{2} p_{3 / 2}$ и ${ }^{2} p_{1 / 2}$-состоянием со спин-орбитальным расщеплением $15.2 \mathrm{eV}$, а также и максимумы от сателлитов, что совпадает с литературным данным [33]. В спектре O $1 s$ кислорода основная линия при энергии связи $529.6 \mathrm{eV}$ отвечает за кислород в решетке $\mathrm{Co}_{3} \mathrm{O}_{4}$ [33], максимум при $531.8 \mathrm{eV}$ связан с адсорбированными $\mathrm{OH}^{-}$-группами [34].

РФЭС-анализ показал, что химический состав поверхности всех образцов полностью идентичен и соответствует стехиометрии $\mathrm{Co}_{3} \mathrm{O}_{4}$.

Таким образом, синтезированные образцы идентичны по химическому составу в объеме и на поверхности, они характеризуются близкими средними значениями диаметров сфер $1.1-1.3 \mu \mathrm{m}$. Полученные результаты позволяют исключить влияние нестехиометрии и кривизны поверхности сфер на магнитные свойства. В то же время образцы № 1-3 отличаются размером наночастиц и плотностью их упаковки в оболочке сфер. Разница в размерах и плотности упаковки наночастиц должны проявиться в магнитных свойствах полых сфер $\mathrm{Co}_{3} \mathrm{O}_{4}$.

При комнатной температуре полевые зависимости намагниченности трех исследованных образцов идентичны и соответствуют парамагнитному состоянию с нулевой коэрцитивностью $\left(H_{c}\right)$ и остаточной намагниченностью $\left(M_{r}\right)$, что совпадает с результатами работы [30]. При $4 \mathrm{~K}$ намагниченность полых сфер в поле
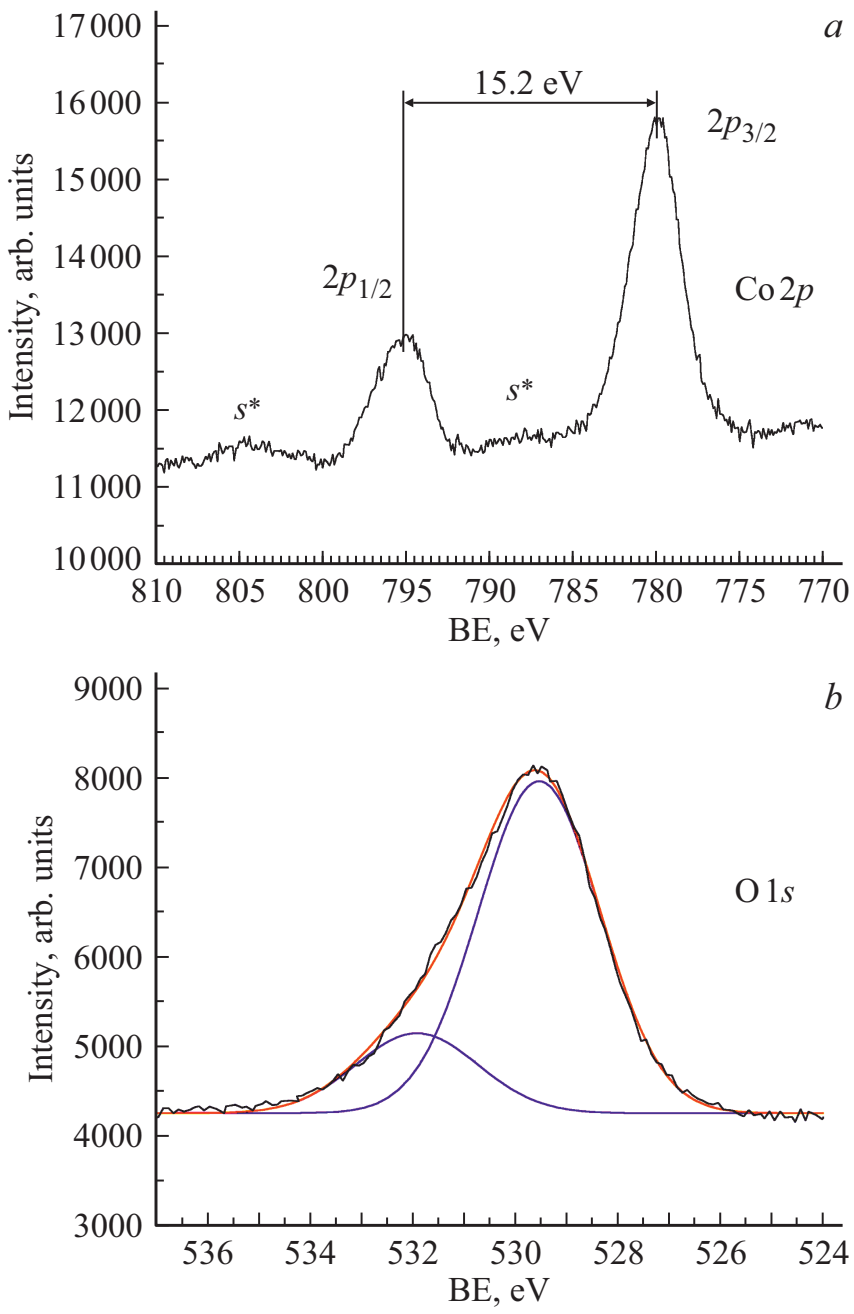

Рис. 4. Спектры РФЭ Со $2 p(a)$ и О $1 s(b)$ образца № 1.

$5 \mathrm{~T}$ составила $3.5 \mathrm{emu} / \mathrm{g}$. Это совпадает с литературными данными для сфер $\mathrm{Co}_{3} \mathrm{O}_{4}$ диаметром $360 \mathrm{~nm}$ [24], хотя диаметр наших сфер практически в 3 раза больше. В образцах № 1 и 2 наблюдается слабый ферромагнетизм с остаточной намагниченностью порядка $0.01 \mathrm{emu} / \mathrm{g}$ и коэрцитивной силой $H_{c}=0.01$ и 0.015 Т для образцов № 1 и 2 соответственно.

Во введении мы отмечали возникновение слабого ферромагнетизма в нанопорошках $\mathrm{Co}_{3} \mathrm{O}_{4}$, связанного с нескомпенсированными поверхностными спинами. Такие наночастицы можно рассматривать как частицы с AFMядром и FM-оболочкой. Наличие такой магнитной структуры приводит к смещению петли магнитного гистерезиса (обменное смещение НЕ) [35]. На рис. 5 представлены центральные части петель, измеренных в режимах заморозки без поля (ZFC) и в поле (FC). В режиме ZFC образец охлаждали в нулевом поле до $4 \mathrm{~K}$ и измеряли намагниченность в интервале полей $\pm 5 \mathrm{~T}$. В режиме FC образцы охлаждали до $4 \mathrm{~K}$ от комнатной температуры в поле 5 Т и измеряли намагниченность в интервале полей \pm 5 T. Можно видеть, что петли гистерезисов FC образцов № 1 и 2 смещается в сторону отрицательного 

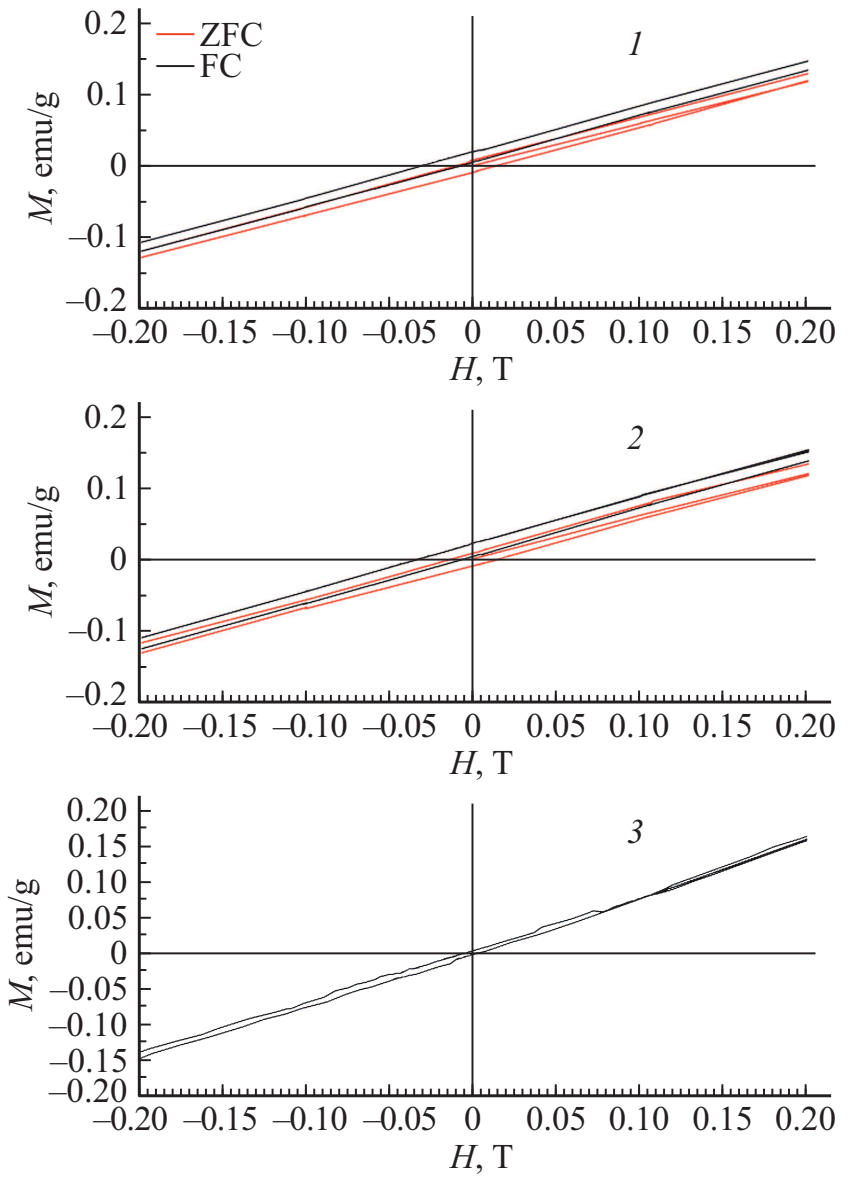

Рис. 5. Полевые зависимости намагниченности при $4 \mathrm{~K}$ для образцов $\mathrm{Co}_{3} \mathrm{O}_{4}$ в режимах $\mathrm{ZFC}$ и $\mathrm{FC}$ в поле $5 \mathrm{~T}(1-$ образец № 1,2 - образец № 2, 3 - образец № 3 ).

поля и положительной намагниченности, в то время как в процессе ZFC петля центрирована относительно начала координат. Сдвиг петли FC обычно связан с обменным смещением. Коэрцитивное поле и поле обменного смещения определяются как $H_{c}=\left(H_{c}^{+}-H_{c}^{-}\right) / 2$ и $H_{E}=\left(H_{c}^{+}+H_{c}^{-}\right) / 2$ соответственно, где $H_{c}^{+}\left(H_{c}^{-}\right)$представляет собой положительное (отрицательное) коэрцитивное поле рис. 5. Результаты измерений представлены в таблице.

Для невзаимодействующих наночастиц наблюдается, как правило, увеличение обменного смещения при уменьшении диаметра частиц [30,35]. В нашем случае эта зависимость не соблюдается. Для образца № 1, сформированного наночастицами меньшего размера, значение $H_{E}$ меньше, чем для образца № 2, состоящего из более крупных частиц. Следует отметить, что обменное смещение определяется не только размером частиц, но и зависит от таких факторов, как доменная структура AFM и FM, шероховатость поверхности [35]. Другим эффектом, который может иметь значение в наноструктурированных системах, является зависимость $H_{E}$ и $H_{C}$ от толщины поверхностного ферромагнитного слоя $t_{\mathrm{FM}}$, в нашем случае представляющий собой интерфейс меж- ду наночастицами. Смещение петли обратно пропорционально толщине слоя FM, $H_{E} \sim 1 / t_{\mathrm{FM}}$ [36]. Увеличение плотности оболочки может привести к уменьшению толщины интерфейса между наночастицами и приводит к увеличению $H_{E}$ и $H_{C}$. Слабый ферромагнетизм и эффект обменного смещения наблюдался в полых сферах диаметром 360 и $680 \mathrm{~nm}$ [24]. Обнаруженное увеличение коэрцитивной силы и обменного смещения при уменьшении диаметра сфер авторы [24] связывают с ростом кривизны поверхности, но, к сожалению, в [24] нет данных о размере и плотности упаковки наночастиц в оболочках сфер. Нельзя исключить влияние кривизны поверхности и в нашем случае. Тем не менее, мы можем утверждать, что это влияние не существенно, так как образцы № 2 и 3 обладают близкими средними диаметрами, но отличаются магнитными характеристиками.

В отличие от образцов № 1 и 2 полевая зависимость намагниченности образца № 3 при $4 \mathrm{~K}$ изменяется линейно с приложенным полем с нулевой коэрцитивной силой и остаточной величиной намагниченности, что соответствует поведению объемного материала ниже температуры Нееля $T_{\mathrm{N}}$ [30]. Отсутствие ферромагнетизма в образце № 3 свидетельствует о малом количестве некомпенсированных магнитных моментов в интерфейсах наночастиц.

Дополнительная информация о магнитной структуре и температурах перехода в антиферромагнитное состояние получена из температурных зависимостей намагниченности, измеренных в режимах ZFC и FC. Для измерения ZFC образец охлаждали от 300 до $2 \mathrm{~K}$ в нулевом магнитном поле, намагниченность регистрировали при нагревании системы в магнитном поле $100 \mathrm{Oe.}$ Для измерения $\mathrm{FC}$ образец охлаждали от 300 до $2 \mathrm{~K}$ в магнитном поле 100 Ое и регистрировалась намагниченность при нагревании системы в том же приложенном магнитном поле. На рис. 6 представлены температурные зависимости намагниченности в режимах ZFC и FC. Для всех образцов ниже $40 \mathrm{~K}$ наблюдаются максимумы. В большинстве работ, исследующих магнитные свойства $\mathrm{Co}_{3} \mathrm{O}_{4}$, температуру максимумов $T_{p} \mathrm{ZFC}$ и FC связывают с температурой Нейля $T_{\mathrm{N}}$ (переходом в антиферромагнитное состояние). Авторы [21] отмечают, что $T_{p}$ на несколько градусов выше $T_{\mathrm{N}}$, тем не менее, отражает изменение $T_{\mathrm{N}}$ при изменении размеров нанокристаллов. Точное значение $T_{\mathrm{N}}$ может быть получено при измерении теплоемкости. Как видно из рис. 6, в ряду образцов № 1-3 наблюдается увеличение температуры максимума от 32 до $38 \mathrm{~K}$.

В магнитных наноматериалах при уменьшении диаметра частиц происходит эффект собственного конечного размера, вызывающий снижение температуры магнитного упорядочения. Для образцов № 1 и 2 наблюдается типичная зависимость $T_{p}$ от размера наночастиц (таблица). Образец № 3 состоит из частиц меньшего диаметра и демонстрирует высокое значение $T_{p}=38 \mathrm{~K}$, совпадающее с таковым для объемного образца [37]. Данный факт позволяет предположить, что температура $T_{\mathrm{N}}$ зависит не 

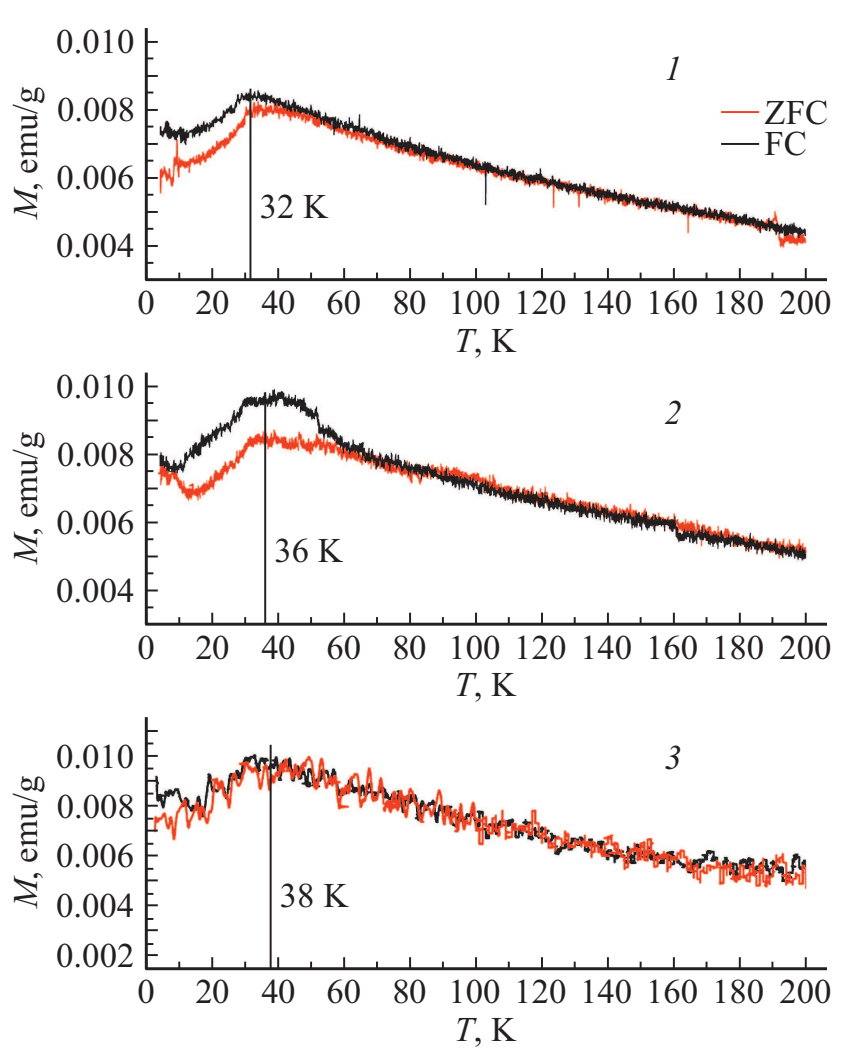

Рис. 6. Температурные зависимости намагниченности образцов $\mathrm{Co}_{3} \mathrm{O}_{4}$ в режимах ZFC и $\mathrm{FC}$ в поле $0.01 \mathrm{~T}(1-$ образец № 1,2 - образец № 2, 3 - образец № 3).

только от размера нанокристаллов, но и от плотности их упаковки в оболочке.

Из кривых $M(T)$ для образцов № 1 и 2 можно выделить характерные особенности, отличающие их от образца № 3. Наблюдается расхождение линий ZFC и FC при температурах $T_{i r r} \sim 70$ и $60 \mathrm{~K}$ соответственно (таблица). Сходное температурно-зависимое поведение намагниченности было зарегистрировано в нескольких экспериментальных кривых $\mathrm{ZFC}-\mathrm{FC}$ для наночастиц $\mathrm{Co}_{3} \mathrm{O}_{4}[17-22,30]$. Расхождение линий ZFC и FC может быть отнесено к спин-стекловидному поведению некомпенсированных спинов на поверхности нанокристаллов. Для образца № 3 зависимости $M(T)$ в режимах ZFC и $\mathrm{FC}$ полностью совпадают, что характерно для объемного образца [37].

Для всех образцов наблюдается увеличение намагниченности при температуре, определяемой как температура замерзания $T_{f}=10 \mathrm{~K}$ (рис. 6). Эта температура связана с замерзанием некомпенсированных поверхностных спинов, о чем неоднократно сообщалось для наночастиц $\mathrm{Co}_{3} \mathrm{O}_{4}$ разного размера и не наблюдается в объемных образцах. Увеличение намагниченности образца № 3 ниже $10 \mathrm{~K}$ является отличительной чертой данного образца от объемного. Наличие низкотемпературного перехода свидетельствует о существовании некомпенсированных поверхностных спинов [38].

\section{4. Заключение}

Метод ультразвукового спрей-пиролиза позволяет создавать функциональные материалы с уникальными свойствами, которые не могут быть получены традиционными методами неорганической химии, путем варьирования химического состава и кристаллического строения. Свойства таких материалов обусловлены размером частиц и формированием между ними границ раздела (интерфейсов). Материал на таких границах находится в особом аморфном состоянии и часто является основным элементом в формировании магнитных свойств. Поиск методов управления интерфейсами может оказаться эффективным способом получения материалов с новыми практически значимыми свойствами.

В настоящей работе методом USP получены полые сферы $\mathrm{Co}_{3} \mathrm{O}_{4}$, обладающие идентичными параметрами решетки и химическим составом с практически равными средними размерами сфер. Отличительными особенностями является размер нанокристаллов, формирующих оболочку полых сфер и плотность их упаковки. Исследование полевых и температурных зависимостей намагниченности таких образцов позволило установить, что магнитные свойства полых сфер определяются не только размером наночастиц, но и плотностью их упаковки. Изменяя плотность упаковки, можно получить сферы с магнитными свойствами характерными как для наночастиц, так и для объемного материала.

\section{Благодарности}

Рентгеновские исследования проводились в лаборатории рентгеноструктурного анализа Института химии твердого тела УрО РАН. Авторы благодарят Е.С. Ульянову и М.В. Кандаурова за съемку КР-спектров.

\section{Финансирование работы}

Работа выполнена в рамках государственного задания научно- исследовательских работ Института химии твердого тела УрО РАН (АААА-А19-119031890026-6).

\section{Конфликт интересов}

Авторы заявляют, что у них нет конфликта интересов.

\section{Список литературы}

[1] D. Sellmyer, R. Skomski. Advanced Magnetic Nanostructures. Springer Science \& Business Media Inc.: New York, N.Y., USA (2006).

[2] S.D. Bader. Rev. Mod. Phys. 78, 1 (2006).

[3] J.I. Martín, J. Nogués, K. Liu, J.L. Vicent, I.K. Schuller. J. Magn. Magn. Mater. 256, 449 (2003).

[4] T. He, D.R Chen, X.L Jiao, Y.L. Wang. Adv. Mater. 18, 1078 (2006).

[5] M. Kläui, C.A.F. Vaz, L. Lopez-Diaz, J.A.C. Bland. J. Phys.: Condens. Matter 15, R985 (2003). 
[6] A. Fert, L. Piraux. J. Magn. Magn. Mater. 200, 338 (1999).

[7] Y.B. Xu, S.M. Thompson. Spintronic Materials and Technology. Taylor \& Francis Group, LLC, London, UK (2007).

[8] V. Raman, S. Suresh, P.A. Savarimuthu, T. Raman, A.M. Tsasakis, K.S. Golokhvast, V.K. Vadivel. Exp. Therap. Med. 11, 2, 553 (2015).

[9] Wei-Chun Lin, Chun-Chao Chuang, Chen-Jung Chang, YaHsu Chiu, Min Yan, Cheng-Ming Tang. Nanomaterials 9, 200 (2019).

[10] X.W. Lou, L.A. Archer, Z.C. Yang. Adv. Mater. 20, 3987 (2008).

[11] M.K. Lima-Tenório, C.S. Ferreira, Q.H.F. Rebelo, R.F.B. de Souza, R.R. Passos, E.A.G. Pineda, L.A. Pocrifka. Mater. Res. 21, 2, e20170521 (2018).

[12] J.G. Yu, X.X. Yu, B.B. Huang, X.Y. Zhang, Y. Dai. Cryst. Growth Des. 9, 1474 (2009).

[13] Z.L. Wu, K. Yu, S.D. Zhang, Y. Xie. J. Phys. Chem. C 112, 11307 (2008).

[14] Y.-E. Chang, D.-Y. Youn, G. Ankonina, D.-J. Yang, H.-G. Kim, A. Rothschild, I.-D. Kim. Chem. Commun. 4019 (2009).

[15] H.T. Zhu, J. Luo, J.K. Liang, G.H. Rao, J.B. Li, J.Y. Zhang, Z.M. Du. Physica B: Condens. Matter 403, 3141 (2008).

[16] B. Raveau, M.M. Seikh. 2012 Electronic and magnetic properties of cobaltites with 3D ,triangular lattice“. Cobalt Oxides: From Crystal Chemistry to Physics (Weinheim: Wiley) (2012). Ch 5. P. 211-247.

[17] Y. Hayakawa, S. Kohiki, M. Sato, Y. Sonda, T. Babasaki, H. Deguchi, A. Hidaka, H. Shimooka, S. Takahashi. Physica E. Low-Dimens. Syst. Nanostruct. 9, 250 (2001).

[18] J.A. Mydosh. Spin Glasses: An Experimental Introduction. Taylor and Francis, London (1993). 280 p.

[19] S. Sarkar, A. Mondal, N. Giri, R. Ray. Phys. Chem. Chem. Phys. 21, 260 (2019).

[20] S. Takada, M. Fujii, S. Kohiki. Nanocrystals Nano Lett. 1, 379 (2001).

[21] P. Dutta, M.S. Seehra, S. Thota, J. Kumar. J. Phys.: Condens. Matter. 20, 015218 (2008).

[22] T. Mousavand, T. Naka, K. Sato, S. Ohara, M. Umetsu, S. Takami, T. Nakane, A. Matsushita, T. Adschiri. Phys. Rev. B. 79, 1 (2009).

[23] S.V. Komogortsev, V.A. Fel'k, O.A. Li. J. Magn. Magn. Mater. 473, 410 (2019).

[24] Q.-L. Ye, H. Yoshikawa, K. Awaga. Materials 3, 2, 1244 (2010).

[25] A.V. Dmitriev, E.V. Vladimirova, M.V. Kandaurov, D.G. Kellerman, A.Yu. Chufarov, A.P. Tyutyunnik. J. All. Comp. 743, 654 ( 2018).

[26] A.V. Dmitriev, E.V. Vladimirova, M.V. Kandaurov, D.G. Kellerman, M.V. Kuznetsov, L.U. Buldakova, R.F. Samigullina. J. All. Comp. 777, 586 (2019).

[27] A.V. Dmitriev, E.V. Vladimirova, M.V. Kandaurov, D.G. Kellerman, A.Yu. Chufarov, N.V. Tarakina, A.P. Tyutyunnik. J. Electr. Mater. 48, 8, 4959 (2019).

[28] А.В. Дмитриев, Е.В. Владимирова, М.В. Кандауров, А.Ю. Чуфаров, Д.Г. Келлерман. ФТТ 59, 2338 (2017).

[29] H.P. Klug, L.E. Alexander. X-ray Diffraction Procedures for Polycrystalline and Amorphous Materials. Wiley-Interscience, N.Y. (1974). 966 p.

[30] S.R. Gawali1, A.C. Gandhi, S.S. Gaikwad, J. Pant, T.-S. Chan, C.-L. Cheng, S.Y. Wu. Sci. Rep. 8, 1 (2018).
[31] R.J. Lang. J. Acoust. Soc. Am. 34, 6, 785 (1962).

[32] I. Lorite, J.J. Romero, J.F. Fernández. J. Raman Spectrosc. 43, 1443 (2012).

[33] D. Cabrera-German, G. Gomez-Sosa, A. Herrera-Gomez. Surf. Interface Anal. 48, 5, 252 (2016).

[34] Y. Xu, Z. Liu, D. Chen, Y. Song, R. Wang. Prog. Natural Sci.: Mater. Int. 27, 2, 197 (2017).

[35] J. Noguesa, J. Sorta, V. Langlaisb, V. Skumryeva, S. Surinachb, J.S. Munozb, M.D. Barob. J. Phys. Rep. 422, 65 (2005).

[36] J.F. Bobo, L. Gabillet, M. Bibes. J. Phys.: Condens. Matter 16, S471 (2004).

[37] S. Thota, S. Singh. Nature of Magnetic Ordering in Cobalt Based Spinels, Magnetic Spinels - Synthesis, Properties and Applications. Mohindar Singh Seehra, Intech Open. (2017).

[38] S. Sarkar, A. Mondal, N. Giri, R. Ray. Phys. Chem. Chem. Phys. 21, 260 (2019).

Редактор К.Е. Емиев 